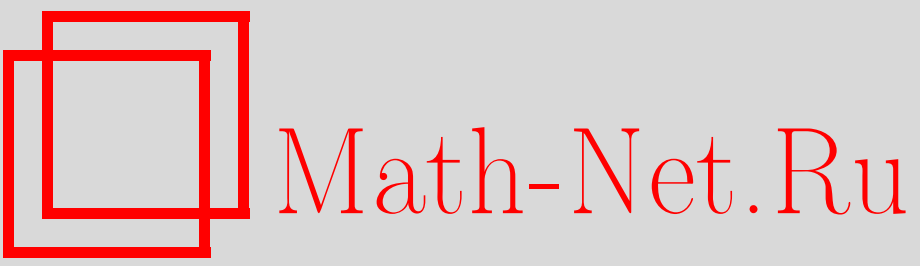

В. М. Сидельников, С. П. Струнков, О некоторых арифметических свойствах орбитных кодов в пространстве матриц, УМH, 1997, том 52, выпуск 6, 185-186

DOI: https://doi.org/10.4213/rm914

Использование Общероссийского математического портала Math-Net.Ru подразумевает, что вы прочитали и согласны с пользовательским соглашением

http://www.mathnet.ru/rus/agreement

Параметры загрузки:

IP: 54.174 .149 .18

26 апреля 2023 г., 15:31:35 


\title{
О НЕКОТОРЫХ АРИФМЕТИЧЕСКИХ СВОЙСТВАХ ОРБИТНЫХ КОДОВ В ПРОСТРАНСТВЕ МАТРИЦ
}

\author{
В. М. СидЕльников, С. П. Струнков
}

Пусть $G$ - конечная группа ортогональных (или унитарных) матриц размера $n \times n$ и $x-$ вектор евклидова (или эрмитова) пространства $V$, на котором естественным образом действует группа $G$, причем норма $\|x\|=1$. Орбита $G x$ вектора $x$ назьвается орбитным кодом (или групповым кодом) $K(G, x)$ [1]. Орбитные коды широко используются при передаче сигналов по каналам связи с шумами. Множество расстояний $D$ кода $K(G, x)$ - это множество всех попарно различных неотрицательных чисел $\left\|g^{\prime} x-g^{\prime \prime} x\right\|, g^{\prime}, g^{\prime \prime} \in G$. Спектром расстояний кода $K(G, x)$ с множеством расстояний $D=\left\{d_{0}=0, d_{1}, \ldots, d_{k}\right\}$ назьвается множество чисел $S=\left\{s_{0}, s_{1}, \ldots, s_{k}\right\}$, в котором каждое число $s_{i}, 0 \leqslant i \leqslant k$, равно числу таких элементов $g x$ орбиты $G x$, расстояние от которых до вектора $x$ равно числу $d_{i}$. Так как группа $G$ действует транзитивно на своей орбите, то это определение вполне согласуется с классическим [3]. Спектр и множество расстояний кода являются его основными параметрами, поэтому задача исследования связей между ними для различных кодов является одной из важнеших в теории кодирования.

Мы рассматриваем здесь орбитные коды

$$
K(G, A)=\{g A ; g \in G\},
$$

в матричном пространстве $W \supset G[2]$, где $A=\left(a_{i, j}\right) \in W$ - произвольная вещественная (комплексная) матрица размера $n \times n$ с евклидовой (соответственно эрмитовой) нормой

$$
\|A\|=\left(\sum_{i, j=1}^{n}\left|a_{i, j}\right|^{2}\right)^{1 / 2}=1 .
$$

Заметим, что орбитные коды, определенные выше, получаются как частный случай орбитных кодов в матричном пространстве, если в качестве матрицы $A$ взять такую матрицу, в которой коэффициенты первого столбца совпадают с координатами вектора $x$, а все остальные элементы равны нулю. Универсальным в некотором смысле орбитным кодом является код $K\left(G, \frac{1}{\sqrt{n}} E\right)$, где $E$ - единичная матрица. Поэтому свойства этого кода интересны в первую очередь. Расстояния в нем и элементы спектра расстояний имеют следующие арифометические связи.

Tеорема. Пусть $D=\left\{d_{0}=0, d_{1}, \ldots, d_{k}\right\}$ - множество расстояни й и $S=\left\{s_{0}=1\right.$, $\left.s_{1}, \ldots, s_{k}\right\}$ - спектр орбитного кода $K\left(G, \frac{1}{\sqrt{n}} E\right)$, где $E-$ единичная матрица. Тогда справедливы следующие утверждения.

1. Число

$$
N_{0}=n^{k} \prod_{i=1}^{k} d_{i}^{2}
$$

является цельм рациональным и при этом делится на порядок $|G|$ группы $G$. Если следь $\operatorname{tr}(g)$ вещественны для всех $g \in G$, то число $N_{0} / 2^{k}$ также является чельм рациональным и также делится на $|G|$.

2. Числа

$$
N_{j}=\frac{1}{|G|} s_{j} n^{k} \prod_{\substack{i=0 \\ i \neq j}}^{k}\left(d_{i}^{2}-d_{j}^{2}\right)
$$

для всех $j, 1 \leqslant j \leqslant k$, являются цельми алгебраическими. Если следы $\operatorname{tr}(g)$ вещественньц для всех $g \in G$, то все числа $N_{j} / 2^{k}$ также являются цельми алгебраическими.

This material is based upon work supported by the U.S. Civilian Research and Development Foundation under Award No. RM-346 and RFBR (№ 96-01-00931). 


\section{СПИСОК ЛИТЕРАТУРЫ}

[1] Slepian D. // Bell Syst. Tech. J. Apr. 1968. V. 47. P. 575-602. [2] Sidelnikov V. M., Strunkov S.P., Klyachko A. A. // Proceedings of Fifth International Workshop on Algebraic and Combinatorial Coding Theory (1-7 June 1996, Sozopol, Bulgaria): Shumen, 1996. Р. 256-258. [3] Мак-Вильямс Ф. Дж., Слоэн Н. Дж. А. Теория кодов, исправляющих ошибки. М.: Связь, 1979.

Московский государственный университет им. М. В. Ломоносова; Московский государственный инженерно-ффизический институт
Принято редколлегией 03.09.1997 